\title{
Effect of various chemical treatments on the fibre structure and tensile properties
} of industrial hemp fibres

Moyeenuddin A. Sawpan ${ }^{a^{*}}$, Kim L. Pickering ${ }^{b}$, Alan Fernyhough ${ }^{c}$

${ }^{a}$ Composite Materials Research, Pultron Composites Ltd, PO Box 323, Gisborne 4040,

New Zealand

${ }^{b}$ Department of Engineering, University of Waikato, Private Bag 3105, Hamilton, New Zealand

${ }^{c}$ Biomaterials Engineering, Biopolymer Network/SCION, Private Bag 3020, Rotorua, New Zealand

\begin{abstract}
Industrial hemp fibres were treated with sodium hydroxide, acetic anhydride, maleic anhydride and silane to investigate the influence of treatment on the fibre structure and tensile properties. It was observed that the average tensile strength of sodium hydroxide treated fibres slightly increased compared with that of untreated fibres, which was believed to be as a result of increased cellulose crystallinity. The average tensile strength of acetic anhydride, maleic anhydride, silane and combined sodium hydroxide and silane treated fibres slightly decreased compared with that of untreated fibres, which was believed to be as a result of decreased cellulose crystallinity. However, the average Young's modulus of all treated fibres increased compared with untreated fibres. This was considered to be as a result of densification of fibre cell walls due to the removal of non-cellulosic components during treatment.
\end{abstract}

Key words: Fibres, Defects, Strength, Surface treatments, Cellulose crystallinity

* Corresponding author. Tel: +64 6867 8582; Fax: +64 68678542

E-mail: moyeen@pultron.com 


\section{Introduction}

Natural fibres such as hemp, sisal, flax, kenaf and jute are highly hydrophilic due to the presence of hydroxyl groups $(\mathrm{OH})$ of anhydroglucose repeating unit in cellulose structure. However, these fibres are covered with pectin and waxy materials, thus hindering the hydroxyl groups from reacting with polymer matrices. This can lead to the formation of ineffective interfaces between the fibres and matrices, with consequent problems such as debonding and voids in resulting composites. Chemical treatments provide an important and effective means to remove non-cellulosic components in cellulose fibres and add functional groups to enable better bonding in polymer composites. In addition, treatment can alter the crystalline structure of the cellulose as well as fibre tensile properties [1-3].

Many chemicals have been screened in laboratory experiments to enhance the potential fibre/matrix interface, such as sodium hydroxide, peroxide, organic and inorganic acids, silane, anhydrides, acrylic monomers [4-8]. Different treatments cause a variation in the degree of impurities removed as well as the degree of structural disruption. In this research work, the influence of various chemicals (sodium hydroxide, acetic anhydride, maleic anhydride and silane) on fibre structure and tensile properties of industrial hemp fibres was investigated by $\mathrm{x}$-ray diffraction and single fibre tensile test.

\section{Materials and methods}

\subsection{Materials}

Industrial hemp fibres were supplied by Hemcore Ltd, UK. [3-(2-aminoethyl amino)propyl]trimethoxy silane and maleic anhydride were purchased from Aldrich and Sigma, respectively. All other chemicals were of analytical grade obtained from local commercial sources.

\subsection{Methods}




\subsubsection{Fibre treatment}

Prior to treatment, untreated fibres (FB) were washed with hot water $\left(50{ }^{\circ} \mathrm{C}\right)$ to remove dirt. Afterwards, fibres were dried in an oven at $80{ }^{\circ} \mathrm{C}$ for $48 \mathrm{~h}$.

\subsubsection{Alkali treatment}

Pre-dried fibres were soaked in $5 \mathrm{wt} \%$ sodium hydroxide solution at ambient temperature, maintaining a solution:fibre ratio of 20:1 (by weight). The fibres were immersed in the solution for $30 \mathrm{~min}$. After treatment, fibres were copiously washed with water to remove any traces of alkali on the fibre surface and subsequently neutralised with $1 \mathrm{wt} \%$ acetic acid solution. The treated fibres (ALK) were then dried in an oven at $80{ }^{\circ} \mathrm{C}$ for $48 \mathrm{~h}$.

\subsubsection{Silane treatment}

A solution of $0.5 \mathrm{wt} \%$ silane coupling agent [3-(2-aminoethyl amino)propyl trimethoxy silane] was prepared in acetone. Acetone was used in preference to water to promote hydrolysis to take place with the moisture on the surface of the fibres rather than within the carrier. It is also reported that acetone promotes swelling of the fibre and so increases the fibre surface area exposed to treatment [9]. The $\mathrm{pH}$ of the solution was adjusted to 3.5 with acetic acid and stirred continuously for $5 \mathrm{~min}$. Fibres (6-7 wt\% moisture content) were then immersed in the solution for $45 \mathrm{~min}$. After treatment, fibres were removed from the solution and dried in oven at $65{ }^{\circ} \mathrm{C}$ for $12 \mathrm{~h}$. Finally, the fibres (SIL) were thoroughly washed with water to remove chemical residues until a $\mathrm{pH}$ of 7 was obtained and then dried in an oven at $80{ }^{\circ} \mathrm{C}$ for $48 \mathrm{~h}$. Similar silane treatment procedures also employed for fibres that were previously alkali treated.

\subsubsection{Maleic anhydride treatment}

Fibres were treated with maleic anhydride at a concentration of $5 \mathrm{wt} \%$ with respect to the weight of fibres. Pre-dried fibres were placed in a round-bottom flask equipped with a water condenser. The calculated amount of maleic anhydride and acetone was 
added to the flask, maintaining a fibre to solution ratio of 1:20 by weight. The flask was refluxed on a heating mantle maintained at a temperature of $65^{\circ} \mathrm{C}$ for $3 \mathrm{~h}$. Thereafter, the fibres were separated from the solvent and washed with acetone to remove unreacted maleic anhydride. Finally, the treated fibres (MA) were washed thoroughly with water to remove residual chemicals and then dried in an oven at $80{ }^{\circ} \mathrm{C}$ for $48 \mathrm{~h}$.

\subsubsection{Acetylation}

Fibres (4-5 wt $\%$ moisture content) were placed in a glass beaker with a sufficient amount of acetic anhydride ensuring that all fibres were totally covered with the reagent to enable the moisture present in the fibres to be hydrolysed by acetic anhydride to acetic acid. Acetic acid improves swelling of fibres increasing the accessibility of hydroxyl groups of the fibres, thus eliminating the need for a solvent [10]. A few drops of sulphuric acid were added to promote the reaction. After 15 minutes, the fibres were removed from the beaker and placed in a pre-heated $\left(120^{\circ} \mathrm{C}\right)$ oven for $2 \mathrm{~h}$ with the aim

of encouraging esterification. Lastly, treated fibres (ACY) were thoroughly washed with water to remove residual chemicals until a $\mathrm{pH}$ of 7 was obtained, and then dried in an oven at $80{ }^{\circ} \mathrm{C}$ for $48 \mathrm{~h}$.

\subsubsection{Fourier transform infrared spectroscopy (FT-IR)}

FT-IR measurements were performed using a Digilab FTS-40 FT-IR spectrometer equipped with a DTGS detector. A total of 30 scans were taken for each sample with a resolution of $4 \mathrm{~cm}^{-1}$. Grounded dried fibre and $\mathrm{KBr}(2 \mathrm{mg}$ fibre per $150 \mathrm{mg} \mathrm{KBr})$ was pressed into a disk for FT-IR measurement.

\subsubsection{X-ray diffraction (XRD)}

The use of XRD counts offers a simple and fast method to calculate the crystallinity index of fibres by means of the empirical Segal equation (Eq.(1)) [11].

$$
I_{X R D}(\%)=\left\lfloor\left(I_{002}-I_{\text {amp }}\right) * 100\right\rfloor / I_{002}
$$


where $I_{X R D}$ crystallinity index, $I_{002}$ is the maximum intensity of the 002 lattice diffraction plane at a $2 \theta$ angle of between $22^{\circ}$ and $23^{\circ}\left(22^{\circ} \leq 2 \theta \leq 23^{\circ}\right)$ and $I_{\text {amp }}$ is the intensity diffraction at an angle $2 \theta$ close to $18^{\circ}$ representing amorphous materials in cellulosic fibres.

For testing, about $15 \mathrm{mg}$ of fibres were cut and pressed into a disk using a cylindrical steel mould with an applied pressure of $10 \mathrm{MPa}$ in laboratory hydraulic press. A Philips X-ray diffractometer, employing $\operatorname{CuK} \alpha(\lambda=1.54)$ radiation and a graphite monochromator with a current of $40 \mathrm{~mA}$ and a voltage of $40 \mathrm{mV}$ was used. The diffraction intensity was in the range of 12 to $45^{\circ}$ of $2 \theta$ (Bragg angle), and the scanning speed was $0.02 \%$ sec.

\subsubsection{Single fibre tensile strength measurement}

Tensile strength of single hemp fibres was measured according to the ASTM D3379-75 Standard Test Method for Tensile Strength and Young's Modulus for High-Modulus Single Filament Materials [12]. Specimens were prepared by separating fibre bundles by hand, and then attaching single fibres to cardboard mounting-cards with $10 \mathrm{~mm}$ holes punched into them using polyvinyl acetate glue to give a gauge length of $10 \mathrm{~mm}$. The diameter was measured at five points along each fibre using an optical microscope with a calibrated eye-piece, and the average diameter was used to calculate the tensile properties of fibres. The mounted fibres were then placed in the grips of an Instron 4204 universal testing machine, and a hot-wire cutter was used to cut the supporting sides of the mounting cards [13].

Tensile testing of the fibres was carried out at a cross-head speed of $0.5 \mathrm{~mm} / \mathrm{min}$ using a 10 N-load cell. The fibres were assumed to have a cylindrical shape. Average strength 
was obtained using the results from thirty five specimens. Young's modulus of single hemp fibres was obtained using a correction factor, based on compliance of the universal testing machine as described in the literature [14].

\subsubsection{Fibre density measurement}

Density of the untreated and treated hemp fibres was measured according to the ASTM D 3800-99 Standard Test Method for Density of High-Modulus Fibres [15]. Benzene was used as immersion liquid [16]. Prior to the measurements, the samples were dried overnight in an oven at $80^{\circ} \mathrm{C}$. The density of the fibres was calculated using Eq. (2).

$$
\rho_{f}=\rho_{l} W_{f a} /\left(W_{f a}-W_{f s}\right)
$$

where $\rho_{l}$ is the density of benzene $\left(0.8765 \mathrm{~g} / \mathrm{m}^{3}\right), W_{f a}$ is the weight of fibre in air and $W_{f s}$ is the weight of fibre in liquid.

\subsubsection{Scanning electron microscope (SEM)}

In this study, fibre surface topography was studied using Hitachi S-4000 and S-4700 field emission scanning electron microscopes. Samples were mounted with carbon tape on aluminium stubs and then sputter coated with platinum and palladium to make them conductive prior to SEM observation.

To examine the transverse cross section of fibres, first the fibres were embedded in a resin block and liquid nitrogen was used to freeze the block. Afterwards, the frozen block was crushed into several pieces for SEM analysis.

\subsubsection{Optical light microscope (OLM)}

In this work, Olympus BX60F5 optical light microscope fitted with a Nikon camera (Digital Sight DS-U1) was used to measure fibre diameter for single fibre tensile testing.

\section{Results and discussion}




\subsection{FT-IR \& SEM analysis of untreated and treated hemp fibres}

Fig. 1 shows FT-IR spectra of the untreated hemp fibres (FB). The strong peak at 3410 $\mathrm{cm}^{-1}$ is characteristic of the hydrogen bonded hydroxyl group $(\mathrm{OH})$ stretching vibration. The peak at $2916 \mathrm{~cm}^{-1}$ was considered due to $\mathrm{C}-\mathrm{H}$ stretching vibration of all hydrocarbon constituents of the fibres and the shoulder band observed at $1732 \mathrm{~cm}^{-1}$ was due to the absorption of carbonyl $(\mathrm{C}=\mathrm{O})$ stretching of hemicellulose present in the fibres. The peak at $1639 \mathrm{~cm}^{-1}$ is related to absorbed water. The peak appearing at 1425 $\mathrm{cm}^{-1}$ was due to $\mathrm{CH}_{2}$ bending in lignin and the peak at $1322 \mathrm{~cm}^{-1}$ was due to $\mathrm{O}-\mathrm{H}$ inplane bending. The band at $1247 \mathrm{~cm}^{-1}$ was considered due to C-O stretching of acetyl in lignin. A small sharp band at $892 \mathrm{~cm}^{-1}$ appears to have arisen from $\beta$-glucosidic linkages between the sugar units in hemicellulose and cellulose [1, 17-20]. A summary of the characteristic peaks is presented in Table 1.

FT-IR spectra of alkali, acetic anhydride and maleic anhydride treated hemp fibres are shown in Fig. 2. In general, the spectrum of alkali treated hemp fibres (ALK) was similar to that of the untreated hemp fibres. However, the peak at $1732 \mathrm{~cm}^{-1}$ seen in untreated fibres disappeared after alkali treatment. This appears to be due to the removal of pectin and hemicellulose present in the fibres $[17,21]$. In alkali treatment, noncelluloses including fats, wax and pectin were removed as can be seen in Fig. 3. Similar observation has also been made by other researchers [17, 22]. Acetylation of hemp fibres with acetic anhydride led to the appearance of a new peak at $1743 \mathrm{~cm}^{-1}$. This was attributed to the C-O stretching of the ester carboxyl group. The lowering in intensity of the $\mathrm{OH}$ stretching band at $3410 \mathrm{~cm}^{-1}$ in the spectra also provided further evidence of successful acetylation [23]. A peak at $1721 \mathrm{~cm}^{-1}$ in the maleated hemp fibres also indicates the presence of the ester groups. There was also a remarkable decrease in the intensity of $\mathrm{OH}$ stretching band at $3410 \mathrm{~cm}^{-1}$ in the spectra, which further confirmed the 
maleation of hemp fibres $[24,25]$. Surface morphology of acetic anhydride and maleic anhydride treated hemp fibres are shown in Fig. 4. It can be observed that nearly all external impurities were removed from the surfaces which appeared to be smooth. This observation is in general agreement with other researchers [23].

Fig. 5 shows FT-IR spectra of silane treated hemp fibres. For both treatments, the characteristic band at $708 \mathrm{~cm}^{-1}$ corresponds to the -Si-O-Si- symmetric stretching and band at $780 \mathrm{~cm}^{-1}$ was corresponding to the $-\mathrm{Si}-\mathrm{C}$ - symmetric stretching. The former band was indicative of polysiloxanes deposited on the fibre and latter points to a condensation reaction between silane and hemp fibres. The well-defined band at 1203

$\mathrm{cm}^{-1}$ was associated with the -Si-O-C- bond confirming the reaction between hydrolysed silane and cellulose of hemp fibres $[6,17]$. However, for combined alkali and silane treated fibres (ALKSIL), the intensity of the band at $1203 \mathrm{~cm}^{-1}$ was higher than that of SIL fibres which suggested that the efficiency of silane grafting onto hemp fibres was higher for the alkali treated fibres compared to the untreated fibres. Gonzalez et al. [6] also made a similar observation for the henequen fibres and silane system. Fig. 6 shows the surface topography of silane treated hemp fibres (SIL and ALKSIL) which appeared to be smooth could be due to the deposition of siloxane to some extent. However, there was no appreciable morphological difference found for the SIL and ALKSIL fibres in the SEM micrographs.

\subsection{XRD analysis of untreated and treated hemp fibres}

X-ray diffractrograms of the treated and untreated fibres are shown in Fig. 7. As can be seen, all the samples showed the characteristic peak of cellulose I $\left(22^{\circ} \leq 2 \theta \leq 23^{\circ}\right)$, which correspond to the 002 crystallographic plane [26]. The other two major peaks at $15.2^{\circ}$ and $16.6^{\circ}$ corresponds to the 101 and $10 \overline{1}$ crystallographic planes, respectively. The measured crystallinity index of the treated and untreated hemp fibres is illustrated 
in Fig. 8. The untreated and different treated fibres showed the following order of crystallinity index: $\operatorname{ALK}(91.6 \%)>\operatorname{ALKSIL}(88.5 \%)>\operatorname{FB}(87.9 \%)>\operatorname{SIL}(86.1 \%)>$ ACY $(84.8 \%)>$ MA (81.8\%). The improved crystallinity index of ALK and ALKSIL fibres compare to FB fibres suggests that treatment with sodium hydroxide removes non-crystalline (amorphous) components from the fibres to some extent. Increase of crystallinity index after sodium hydroxide treatment has also been observed elsewhere $[1,13,21,22]$, and explained by the removal of non-cellulosic materials enabling better packing of cellulose chains. On the other hand, the crystallinity index of the SIL, ACY and MA fibres decreased compared with that of FB fibres, and crystallinity index of ALKSIL fibre is reduced compared to ALK fibres. This was probably due to the increase of amorphous cellulose content upon acetic anhydride, maleic anhydride and silane treatment. According to the literature [23], the reaction between different chemical reagents with cellulose takes place mainly in the amorphous cellulose regions or at the edges of crystalline cellulose regions; the reagents first react with the chain ends on the surface of crystallites, as they cannot diffuse into crystalline region, resulting in the opening of some of the hydrogen-bonded cellulose chains. This results in some conversion of crystalline to amorphous cellulose. The reagent then diffuses into this newly produced amorphous section, reacting with the crystalline cellulose and simultaneously generating more amorphous cellulose.

\subsection{Fibre density}

Density of the untreated and treated hemp fibres is presented in Table 2. It can be observed that the density of hemp fibres increased after treatment. This could be due to the (i) densification of fibre cell walls as a result of removal of impurities (less dense fats and waxes) by solvents and (ii) filling of the pores with grafted molecules (except the alkali treated fibres) [27]. Mwaikambo et al. [2] also found that the density of hemp fibres increased upon alkali treatment. In another work, Varma et al. [27] treated jute 
fibres with various chemicals including silane, titanate, sebacoyl chloride and tolylene diisocyanate and found that the fibre density increased after treatment.

\subsection{Defects in industrial hemp fibres}

The cell walls of natural fibres contain defects, known as kink bands and microcompressive defects [28]. At the defect region, the angle of the microfibrils relative to the fibre axis differs from the angle of the surround cell wall, which corresponds to the change of crystalline orientation. In general, defects in natural fibres arise from two different sources namely (1) during growth, and (2) during the process of decortication by which the fibres are separated from the plant. In a typical decortication process, retted basts are passed between fluted rollers and/or fed through a bladed thresher to break up the woody core and separate the fibres. This results in a high level of introduced defects in the elementary fibres. Such defects significantly retard fibre strength and are responsible for much of the variability in fibre tensile strength and Young's modulus.

A number of features, similar to those seen in other natural fibres [28, 29], were noted in industrial hemp fibres of the present study. For example, the presence of kink bands in hemp fibres can be seen in Fig. 9(a) which were often found at the same place on various fibres of a bundle. It is reported that the kink bands are the most likely area to break during the tensile tests of fibres. Kink bands would suggest a loss of tensile strength in the fibres [28]. In Fig. 9(b), micro-cracks in fibre cell wall along the fibre length were evident (shown in small box). It was unclear how deep the crack penetrated into the fibre cell wall. Light microscope images of micro-compressive defects (indicated by arrows) in hemp fibres are shown in Fig.10. The damage appeared to be extensive, occurring at frequent intervals along the length of the fibre. 
Hughes et al. [30] have shown that micro-compressive defects can be present in both 'green' (separated by hand) and 'processed' (by decortication) hemp fibres. In another report, Davies and Bruce [31] studied the relationship between tensile properties and the amount of defects for flax and nettle fibres. They observed that tensile properties of the fibres decreased to some extent as the number of defects increased.

\subsection{Single fibre tensile properties of untreated and treated hemp fibres}

Fig. 11 shows typical stress-displacement curves for single fibres. The failure strain of single fibres was found to be approximately $1-2 \%$. The average diameter of the untreated and treated fibres is presented in Table 2. As expected, the average diameter of all treated fibres decreased compared to untreated fibres due to the removal of surface impurities (wax, pectin and fat) as discussed in section 3.1.

The average tensile strength and Young's modulus of the treated hemp fibres is illustrated in Fig. 12. It can be seen that the alkali treatment appeared to slightly increase the tensile strength of the fibres in relation to those of the untreated fibres, whereas the other treatments appeared to slightly reduce the tensile strength of hemp fibres. The order of average tensile strength is: ALK $(598 \mathrm{MPa})>$ FB $(577 \mathrm{MPa})>$ ALK/SIL $(565 \mathrm{MPa})>\operatorname{SIL}(554 \mathrm{MPa})>\operatorname{ACY}(546 \mathrm{MPa})>\mathrm{MA}(538 \mathrm{MPa})$. On the other hand, the Young's modulus of various treated fibres appeared to slightly increase when compared with that of untreated fibres. The order of average Young's modulus is: $\operatorname{ALK}(33.8 \mathrm{GPa})>\operatorname{ALK} / \operatorname{SIL}(31.7 \mathrm{GPa})>\operatorname{SIL}(29.9 \mathrm{GPa})>\operatorname{ACY}(29.1 \mathrm{GPa})>\mathrm{MA}$

$(28.3 \mathrm{MPa})>\mathrm{FB}(26.5 \mathrm{GPa})$. Statistical analysis did not support a significant difference in tensile strength and Young's modulus of the different treated fibres when compared with those of the untreated fibres, although given the high variability of data, this is not surprising. It must be accepted that experimental error as well as fibre structure will have influenced variability. The transverse cross-sectional area of the fibres was 
assumed to be circular, although the single hemp fibres were polygonal shape as can be seen in Fig. 13. This assumption would be a source of error in the measured tensile properties of the untreated and treated fibres which would have increased measured variability. In section 3.4, it was seen that hemp fibres had many defects along their length. These defects could be another reason for large scatter in tensile strength and Young's modulus results.

Increase in tensile strength of ALK fibres could be occurring due to the improvement of cellulose chain packing order. As stated in the literature [18], alkali treatment of natural fibres causes a reduction in the spiral angle of cellulose microfibrils which in turn allowed for the rearrangement of the cellulose chains and consequently improves tensile strength. Unlike alkali treatment, silane and acetylation were carried out in acidic medium. This acidic medium could catalyse the cleavage of $\beta$-1,4-glycosidic bonds between the two anhydroglucose units. Thus cellulose chain scission could be lowering the tensile strength of hemp fibres [32]. In the case of maleic anhydride modified fibres (MA), fibres were heated in the presence of a solvent (i.e. acetone). Decrease in tensile strength of MA fibres could be occurring due to the weakening of interfibrillar interaction in cellulose due to heating in the presence of the solvent. Weakening (or softening) of interfibrillar interaction in MA fibres have been seen to adversely affect the stress transfer between fibrils and thereby the overall stress development in fibres under tensile deformation [2]. Fibre treatment causes dissolution of soft materials (e.g. wax, gum and pectin) as supported by SEM which could slight increase in Young's modulus by fibre cell wall densification on elimination of these materials.

Relationships between the tensile properties and crystallinity index for treated and untreated hemp fibres are shown in Fig. 14. As can be observed, tensile strength and 
Young's modulus of hemp fibres increased with increased crystallinity index. A similar relationship was observed for alkali treated jute fibre as reported by Gassan et al. [33]. On the other hand, Mwaikambo et al. [34] found contradicting results for alkali treated sisal fibres such that tensile strength and Young's modulus decreased with increased crystallinity index. Such contradicting results suggest that treatment severity has a large influence on tensile properties; it may be that at higher levels of treatment, chain scission may override the influence of increased crystallinity and result in lower tensile properties.

\section{Conclusions}

The average tensile strength of sodium hydroxide treated fibres (ALK) slightly increased compared with that of untreated fibres, which was believed to be as a result of increased cellulose crystallinity. In contrast, the average tensile strength of acetic anhydride, maleic anhydride and silane treated fibres slightly decreased compared with that of untreated fibres, which was believed to be as a result of decreased cellulose crystallinity. In the case of a combined treatment with sodium hydroxide and silane, the average tensile strength of the fibres (ALKSIL) slightly decreased compared to that of alkali only treated fibres (ALK), which was also thought to be as a result of decreased cellulose crystallinity. The average Young's modulus of all the treated fibres increased slightly compared with that of the untreated fibres, which was considered to be due to densification of fibre cell walls as a result of removal of non-cellulosic materials during treatment as supported by SEM. Defects were observed for hemp fibres that could explain much of the variability in fibre tensile strength and Young's modulus.

\section{Acknowledgement}

The financial support from Biopolymer Network Ltd, New Zealand for this work is greatly acknowledged.

\section{References}


[1] D. Ray, and B. K. Sarkar, Characterization of alkali-treated jute fibers for physical and mechanical properties, Journal of Applied Polymer Science 80 (2001) 1013-1020. [2] L. Y. Mwaikambo, and M. P. Ansell, Mechanical properties of alkali treated plant fibres and their potential as reinforcement materials. I. Hemp fibres, Journal of Materials Science 41 (2006) 2483-2496.

[3] E. Sinha, and S. Rout, Influence of fibre-surface treatment on structural, thermal and mechanical properties of jute, Journal of Materials Science 43 (2008) 2590-2601.

[4] I. Van de Weyenberg, T. Chi Truong, B. Vangrimde, and I. Verpoest, Improving the properties of UD flax fibre reinforced composites by applying an alkaline fibre treatment, Composites Part A: Applied Science and Manufacturing 37 (2006) 13681376.

[5] J. B. Naik, and S. Mishra, Esterification effect of maleic anhydride on swelling properties of natural fiber/high density polyethylene composites, Journal of Applied Polymer Science 106 (2007) 2571-2574.

[6] A. Valadez-Gonzalez, J. M. Cervantes-Uc, R. Olayo, and P. J. Herrera-Franco, Chemical modification of henequen fibers with an organosilane coupling agent, Composites Part B:Engineering 30 (1999) 321-331.

[7] V. Tserki, C. Panayiotou, and N. E. Zafeiropoulos, A study of the effect of acetylation and propionylation on the interface of natural fibre biodegradable composites, Advanced Composites Letters 14 (2005) 65-71.

[8] J. Rout, M. Misra, and A. K. Mohanty, Surface modification of coir fibers I: Studies on graft copolymerization of methyl methacrylate on to chemically modified coir fibers, Polymers for Advanced Technologies 10 (1999) 336-344.

[9] K. L. Pickering, A. Abdalla, C. Ji, A. G. McDonald, and R. A. Franich, The effect of silane coupling agents on radiata pine fibre for use in thermoplastic matrix composites, Composites Part A: Applied Science and Manufacturing 34 (2003) 915-926. 
[10] N. E. Zafeiropoulos, D. R. Williams, C. A. Baillie, and F. L. Matthews, Engineering and characterisation of the interface in flax fibre/polypropylene composite materials. Part I. Development and investigation of surface treatments, Composites Part A: Applied Science and Manufacturing 33 (2002) 1083-1093.

[11] M. Le Troedec, D. Sedan, C. Peyratout, J. P. Bonnet, A. Smith, R. Guinebretiere, V. Gloaguen, and P. Krausz, Influence of various chemical treatments on the composition and structure of hemp fibres, Composites Part A: Applied Science and Manufacturing 39 (2008) 514-522.

[12] Standard Test Method for Tensile Strength and Young's Modulus for HighModulus Single-Filament Materials, ASTM D 3379 (1989).

[13] K. L. Pickering, G. W. Beckermann, S. N. Alam, and N. J. Foreman, Optimising industrial hemp fibre for composites, Composites Part A (Applied Science and Manufacturing) 38 (2007) 461-468.

[14] G. Beckermann, Performance of Hemp-Fibre Reinforced Polypropylene Composite Materilas, PhD Thesis, University of Waikato (2007).

[15] Standard Test Method for Density of High-Modulus Fibers, ASTM D 3800-99 (1999).

[16] L. Y. Mwaikambo, and M. P. Ansell, The determination of porosity and cellulose content of plant fibers by density methods, Journal of Materials Science Letters 20 (2001) 2095-2096.

[17] L. A. Pothan, C. Bellman, L. Kailas, and S. Thomas, Influence of chemical treatments on the electrokinetic properties of cellulose fibres, Journal of Adhesion Science and Technology 16 (2002) 157-178.

[18] I. Taha, L. Steuernagel, and G. Ziegmann, Optimization of the alkali treatment process of date palm fibres for polymeric composites, Composite Interfaces 14 (2007) 669-684. 
[19] M. Das, and D. Chakraborty, Influence of alkali treatment on the fine structure and morphology of bamboo fibers, Journal of Applied Polymer Science 102 (2006) 50505056.

[20] D. L. Pavia, G. M. Lampman, G. S. Kriz, and J. A. Vyvyan, Introduction to Spectroscopy (4th Edition), Brooks Cole (2008).

[21] S. Ouajai, and R. A. Shanks, Composition, structure and thermal degradation of hemp cellulose after chemical treatments, Polymer Degradation and Stability 89 (2005) $327-335$.

[22] L. Y. Mwaikambo, and M. P. Ansell, Chemical modification of hemp, sisal, jute, and kapok fibers by alkalization, Journal of Applied Polymer Science 84 (2002) 22222234.

[23] V. Tserki, N. E. Zafeiropoulos, F. Simon, and C. Panayiotou, A study of the effect of acetylation and propionylation surface treatments on natural fibres, Composites Part A (Applied Science and Manufacturing) 36 (2005) 1110-1118.

[24] G. Cantero, A. Arbelaiz, R. Llano-Ponte, and I. Mondragon, Effects of fibre treatment on wettability and mechanical behaviour of flax/polypropylene composites, Composites Science and Technology 63 (2003) 1247-1254.

[25] S. Nenkova, G. Simeonova, T. Dobrilova, S. Vasilieva, and M. Natov, Modification of wood and wood flour with maleic anhydride, Cellulose Chemistry and Technology 38 (2004) 375-383.

[26] B. A. P. Ass, M. N. Belgacem, and E. Frollini, Mercerized linters cellulose: Characterization and acetylation in N,N-dimethylacetamide/lithium chloride, Carbohydrate Polymers 63 (2006) 19-29.

[27] I. K. Varma, S. R. Anantha Krishnan, and S. Krishnamoorthy, Effect of chemical treatment on density and crystallinity of jute fibers, Textile Research Journal 59 (1989) 368-370. 
[28] C. Baley, Influence of kink bands on the tensile strength of flax fibers, Journal of Materials Science 39 (2004) 331-334.

[29] D. Ruys, A. Crosky, and W. J. Evans, Natural bast fibre structure, International Journal of Materials and Product Technology 17 (2002) 2-10.

[30] M. Hughes, G. Sebe, J. Hague, C. Hill, M. Spear, and L. Mott, An investigation into the effects of micro-compressive defects on interphase behaviour in hemp-epoxy composites using half-fringe photoelasticity, Composite Interfaces 7 (2000) 13-29. [31] G. C. Davies, and D. M. Bruce, Effect of environmental relative humidity and damage on the tensile properties of flax and nettle fibers, Textile Research Journal 68 (1998) 623-629.

[32] A. Arbelaiz, G. Cantero, B. Fernandez, I. Mondragon, P. Ganan, and J. M. Kenny, Flax fiber surface modifications: effects on fiber physico mechanical and flax/polypropylene interface properties, Polymer Composites 26 (2005) 324-332.

[33] J. Gassan, and A. K. Bledzki, Alkali treatment of jute fibers: relationship between structure and mechanical properties, Journal of Applied Polymer Science 71 (1999) 623-629.

[34] L. Y. Mwaikambo, and M. P. Ansell, Mechanical properties of alkali treated plant fibres and their potential as reinforcement materials. II. Sisal fibres, Journal of Materials Science 41 (2006) 2497-2496. 


\section{Figure captions}

Fig.1. FT-IR spectrum of untreated hemp fibre.

Fig. 2. FT-IR spectra of alkali, acetic anhydride and maleic anhydride treated hemp fibres.

Fig. 3. SEM micrographs of the surface morphology of: (a) untreated and (b) alkali treated hemp fibres.

Fig. 4. SEM micrographs of the surface morphology of: (a) acetic anhydride and (b) maleic anhydride treated hemp fibres.

Fig. 5. FT-IR spectra of silane treated hemp fibres.

Fig. 6. SEM micrographs of the surface morphology of: (a) SIL and (b) ALKSIL.

Fig. 7. X-ray diffractogram of untreated and treated hemp fibres.

Fig. 8. XRD crystallinity index of untreated and treated hemp fibres.

Fig. 9. SEM micrographs showing kink bands in hemp fibres.

Fig. 10. Light microscopic images of micro-compressive defects in hemp fibres.

Fig. 11. Typical stress-displacement curves of single hemp fibres.

Fig. 12. Tensile strength and Young's modulus of untreated and treated hemp fibres.

Fig. 13. SEM micrographs of transversal cross-section of hemp fibres showing variability of shape and size.

Fig. 14. Relationships of tensile strength and Young's modulus with fibre crystallinity. 


\section{Table captions}

Table 1: FT-IR transmittance peaks for untreated and treated hemp fibres.

Table 2: Average diameter and density of the untreated and treated hemp fibres 


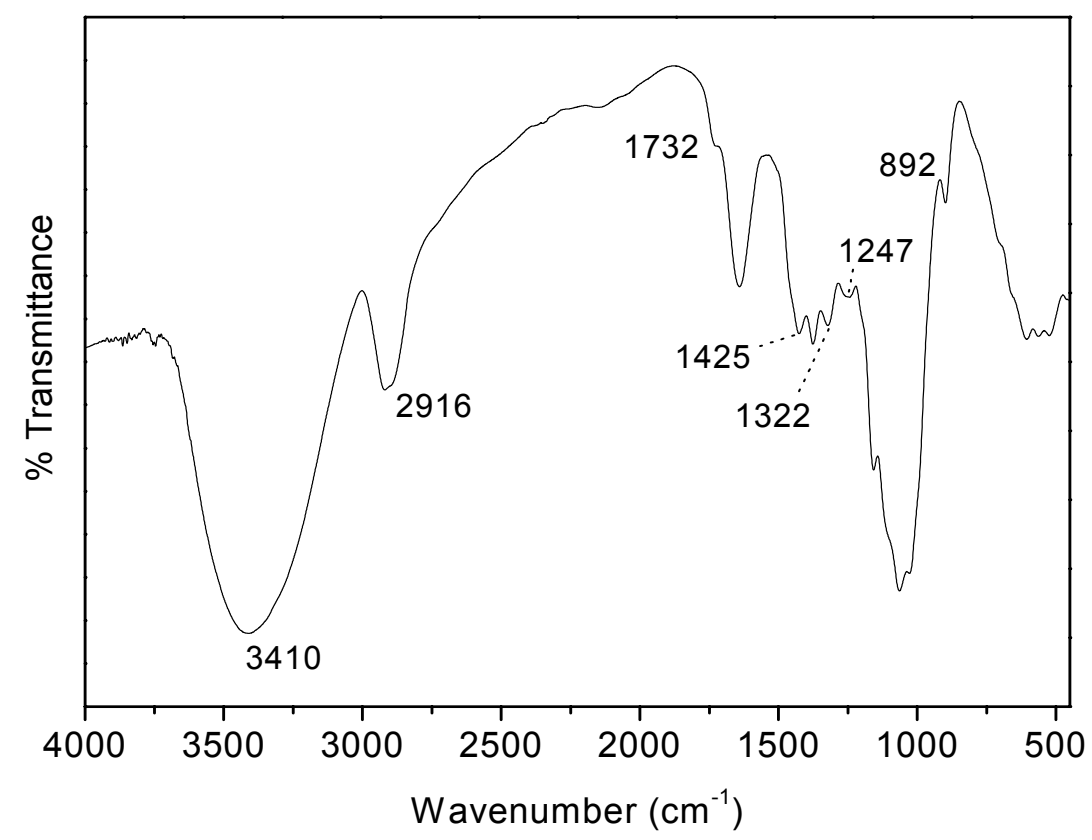

Fig.1.

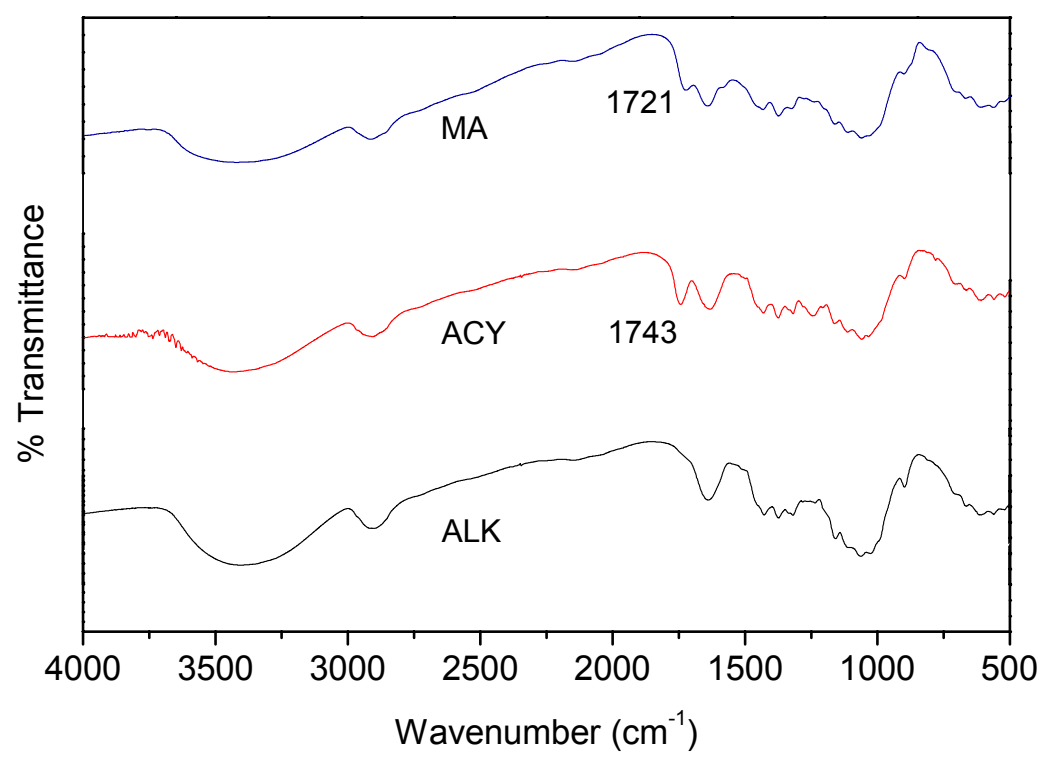


Fig. 2.
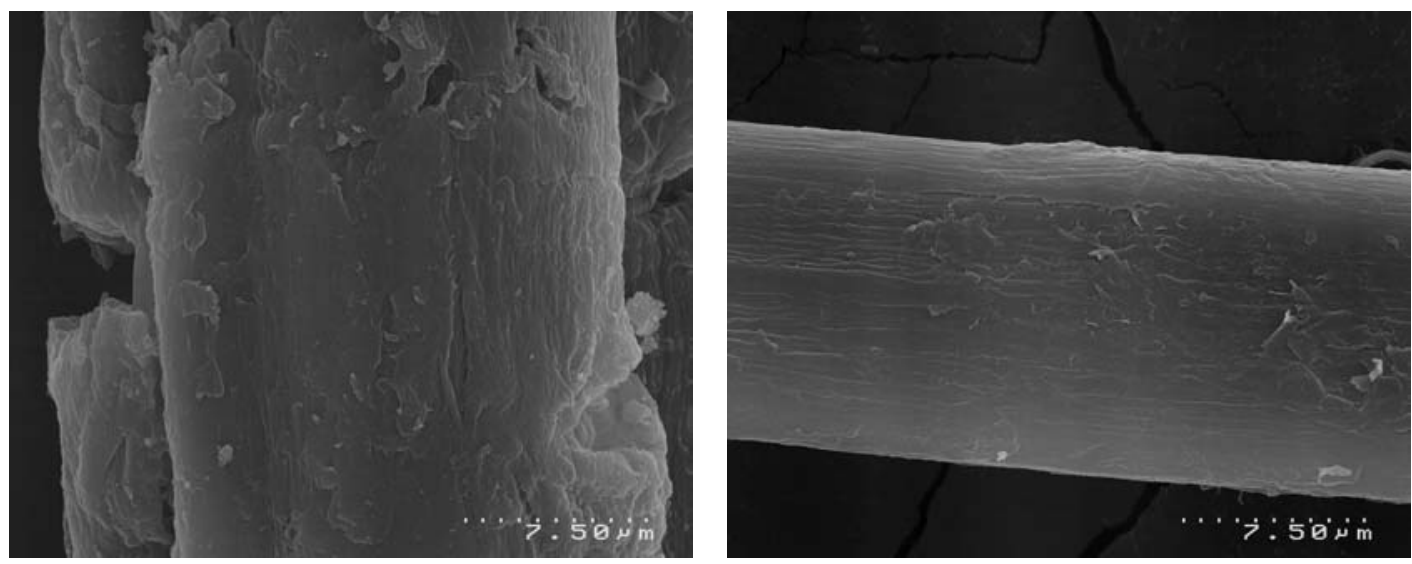

(a)

(b)

Fig. 3.
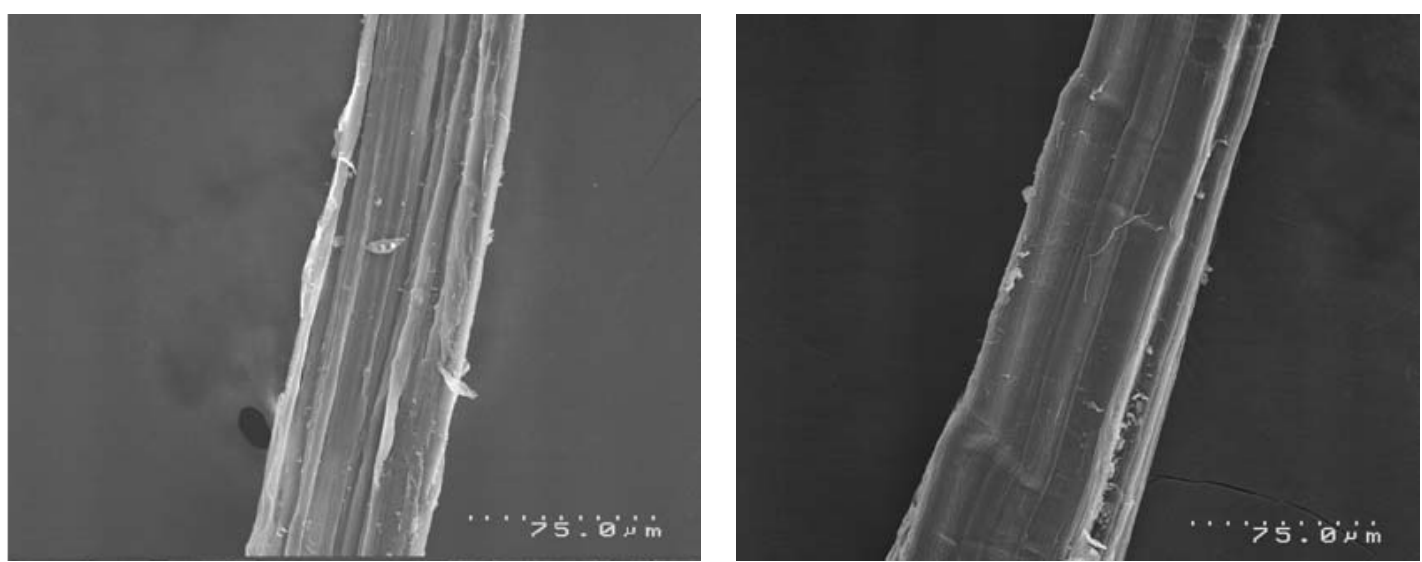

(a)

(b)

Fig. 4. 


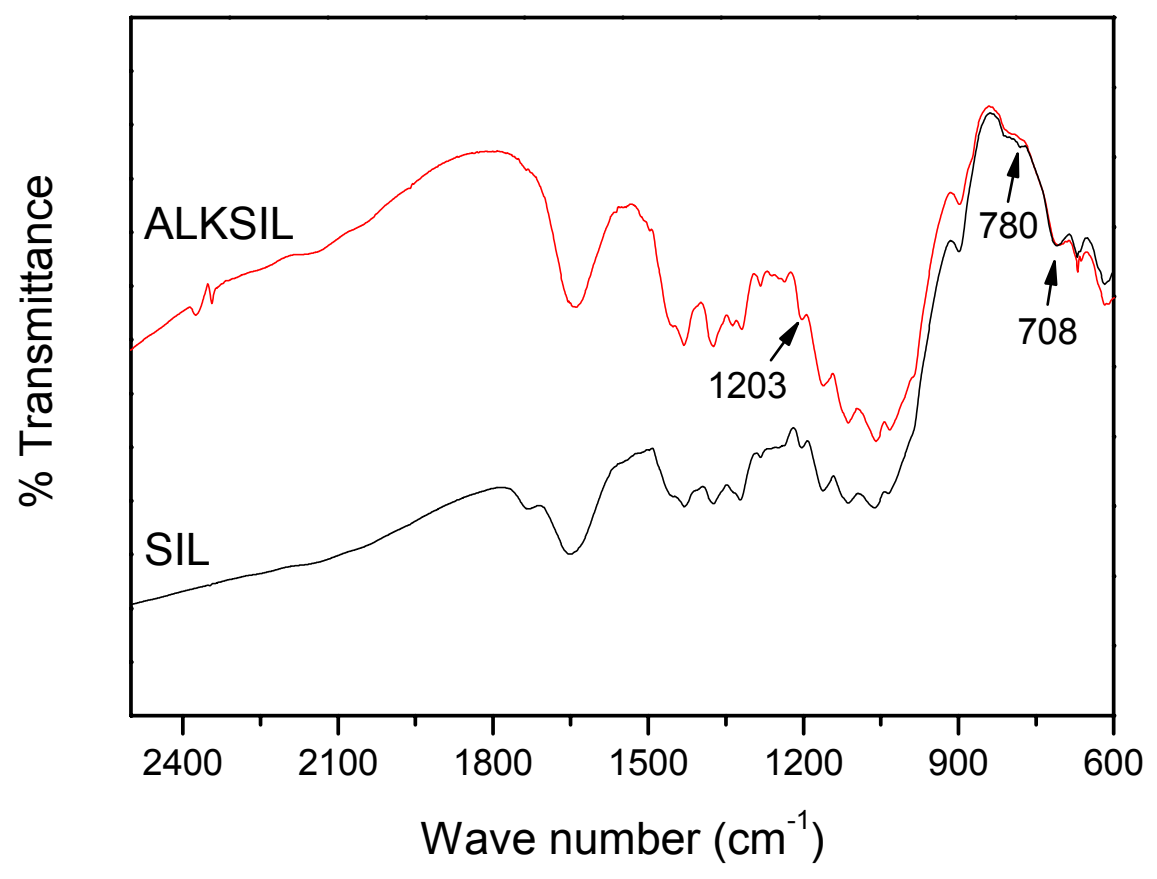

Fig. 5.

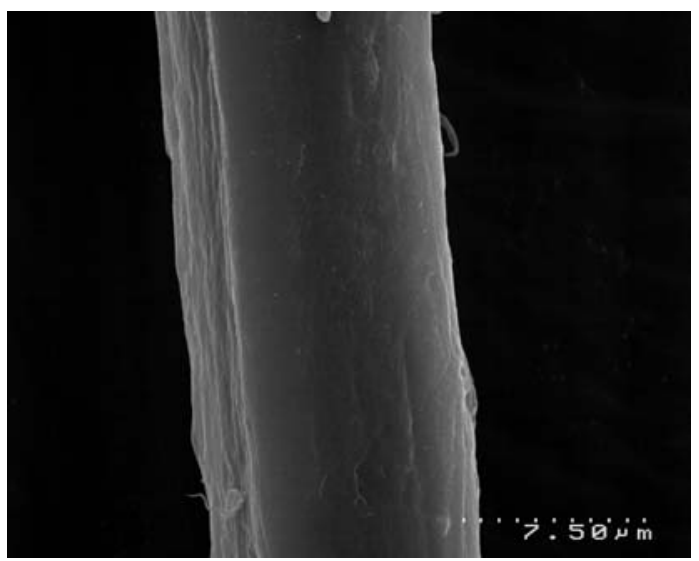

(a)

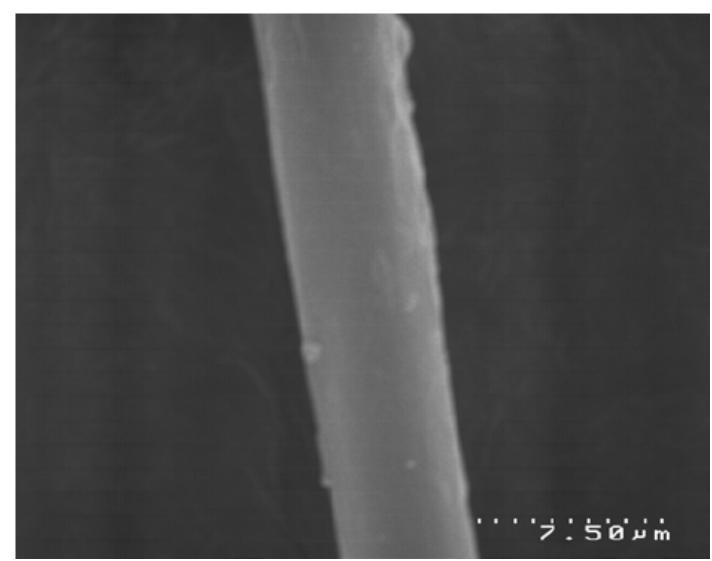

(b)

Fig. 6 . 


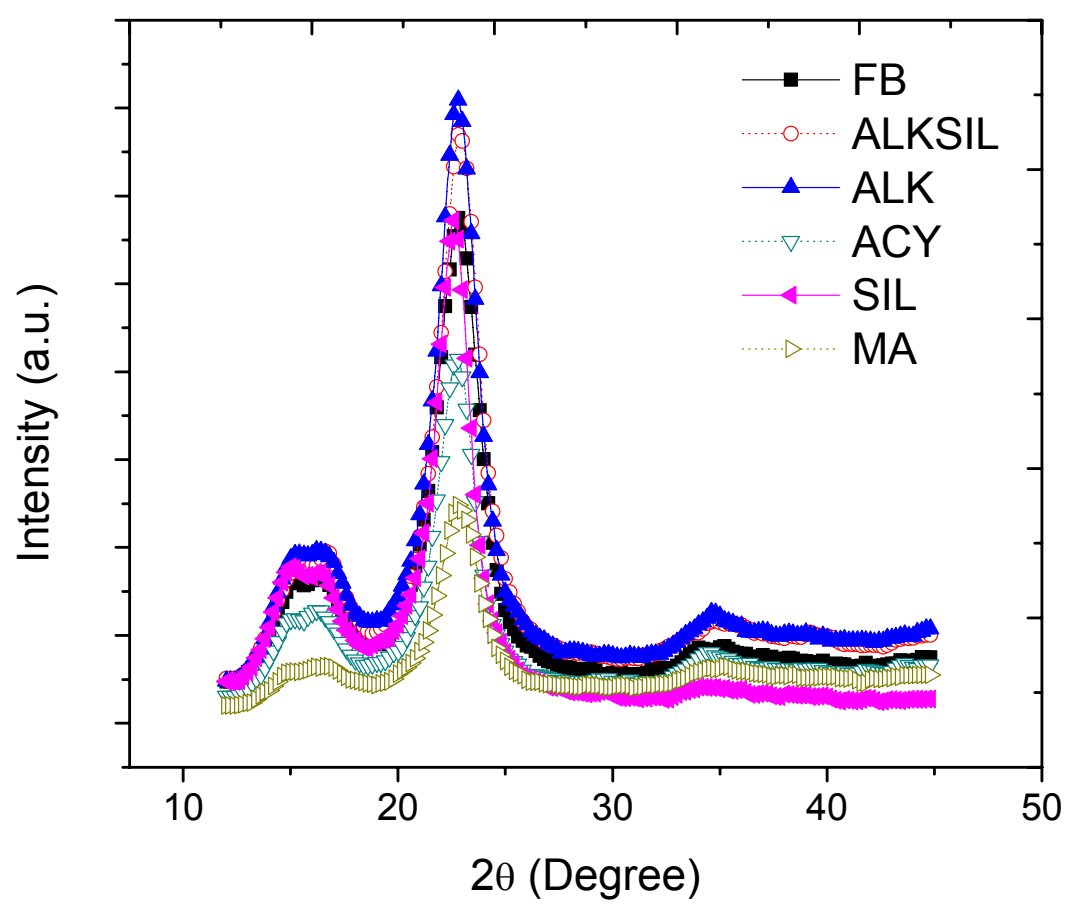

Fig. 7.

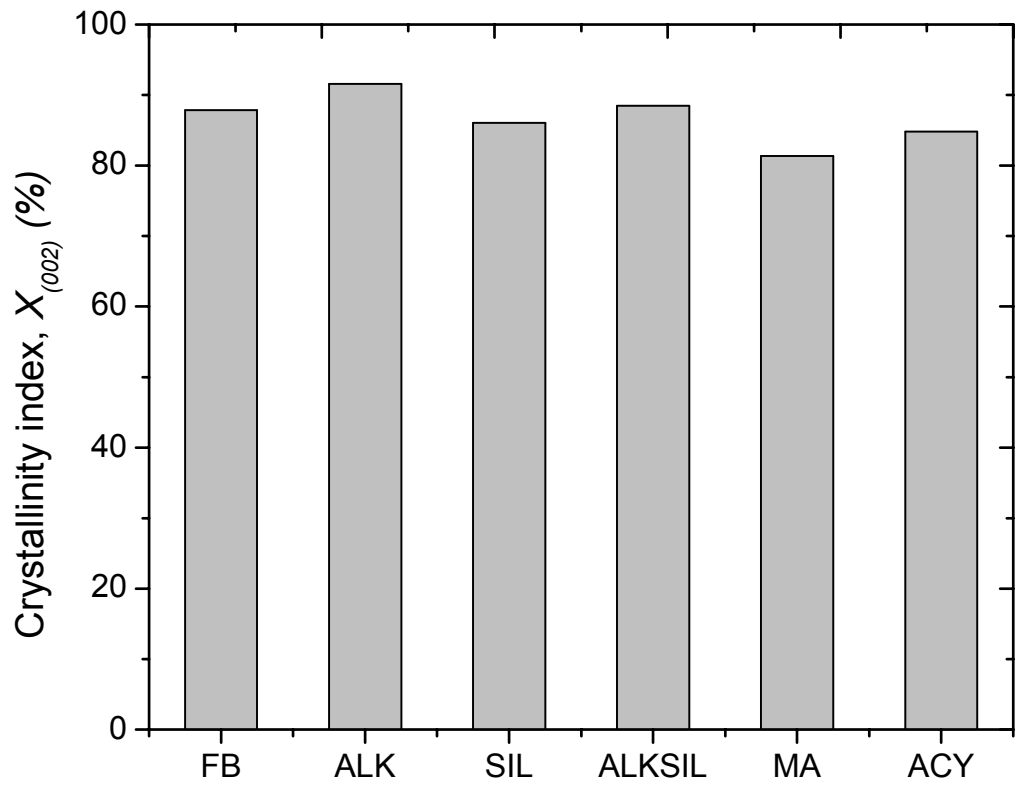

Fig. 8 . 

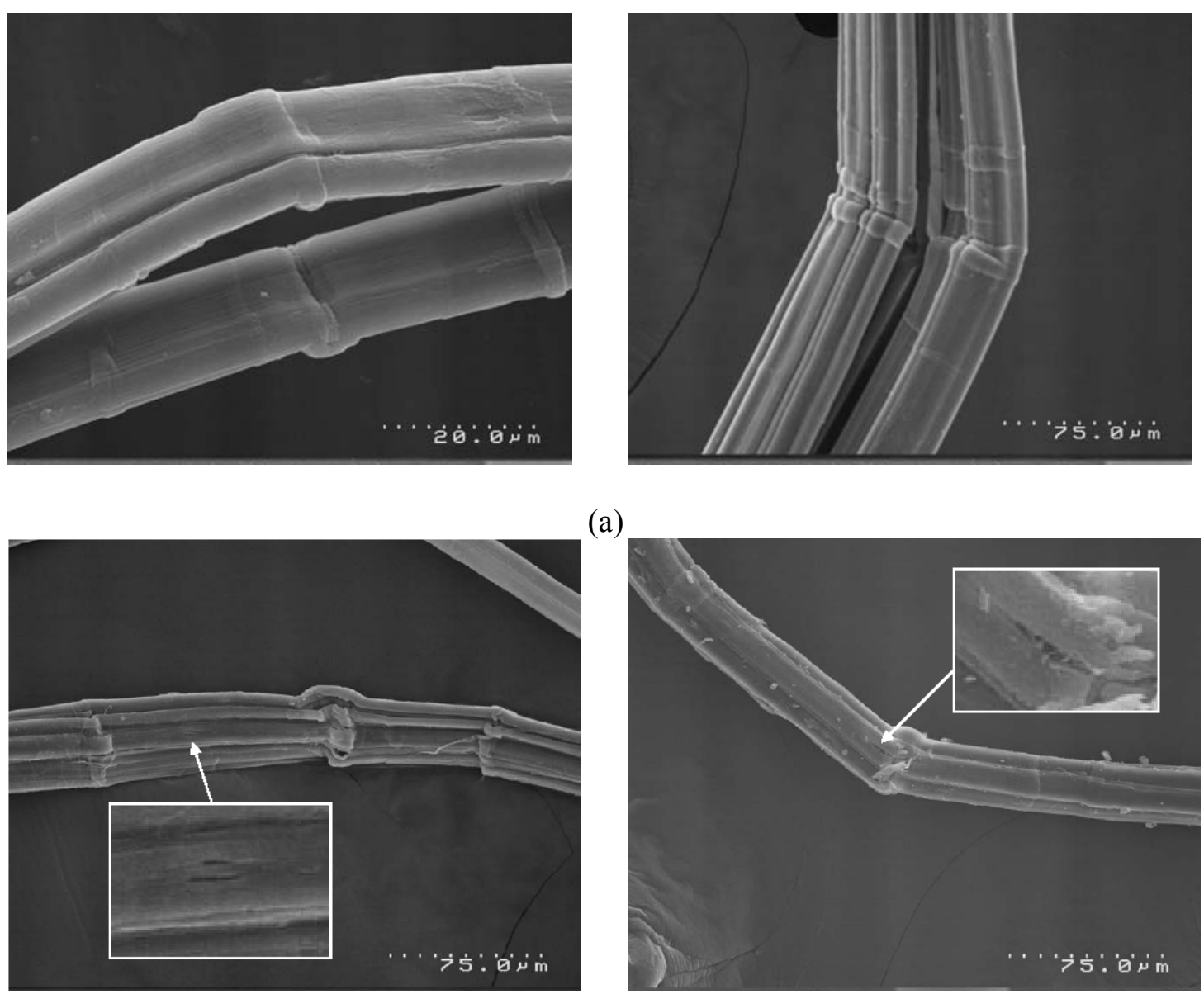

(a)

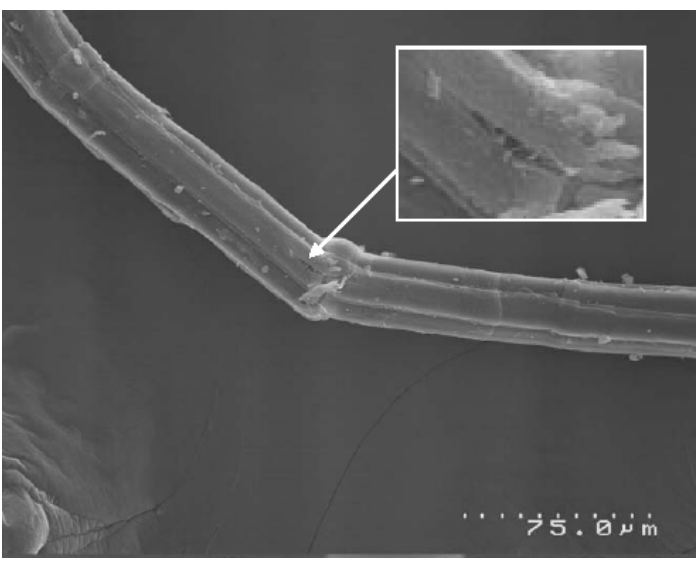

(b)

Fig. 9.
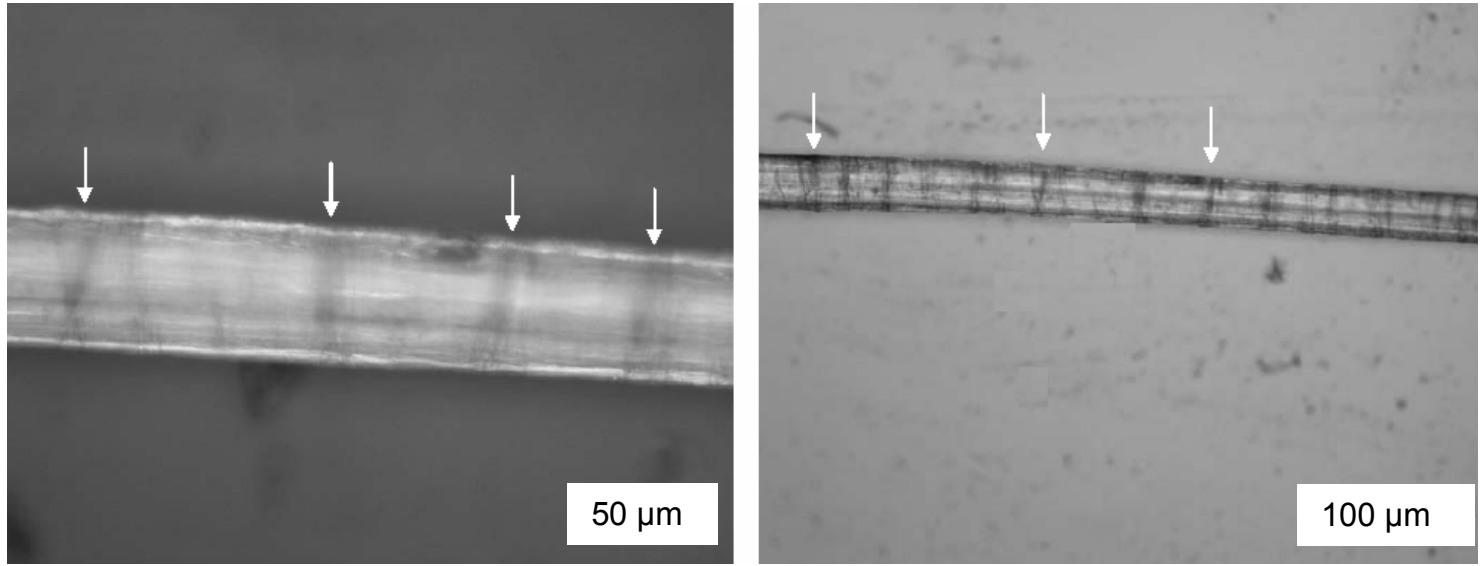

Fig. 10 . 


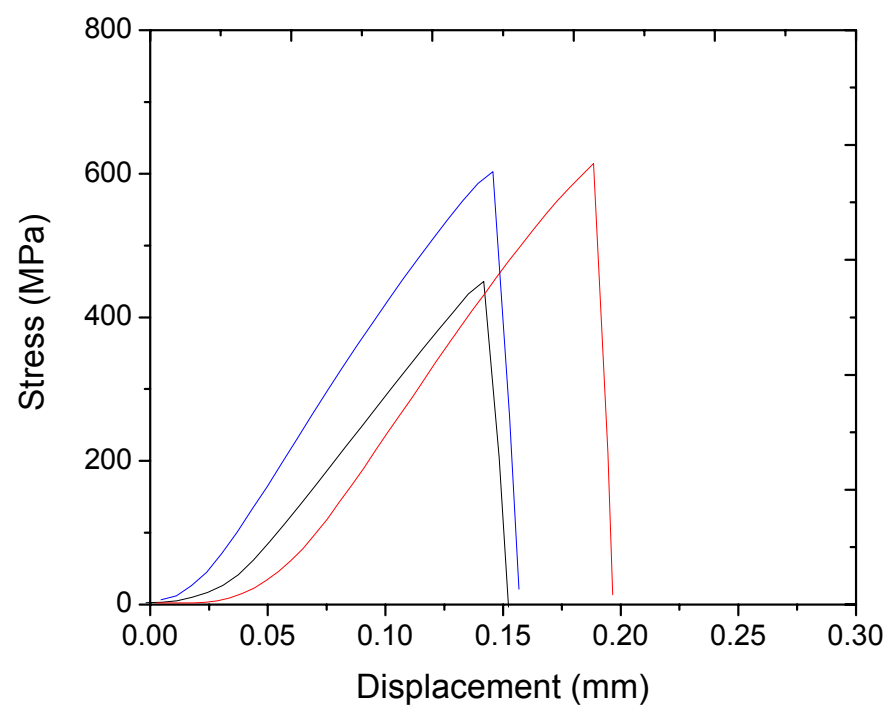

Fig. 11.
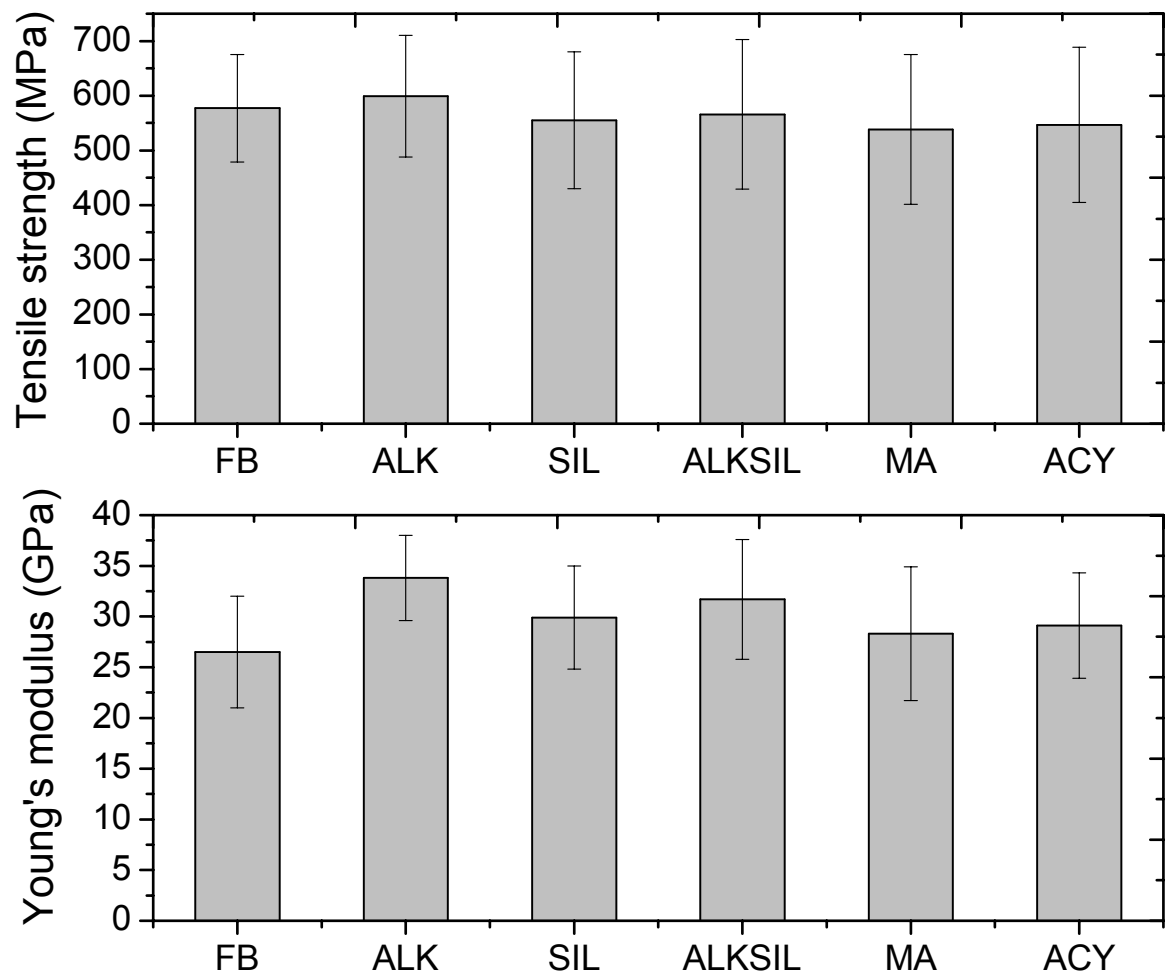

Fig. 12. 

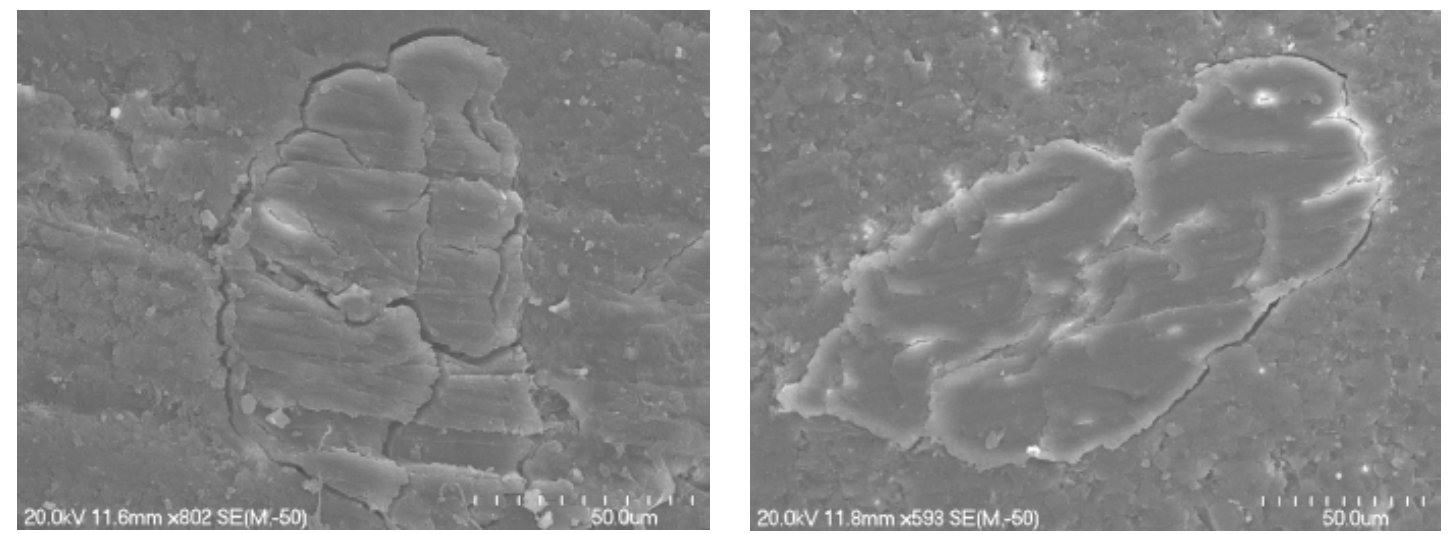

Fig. 13.
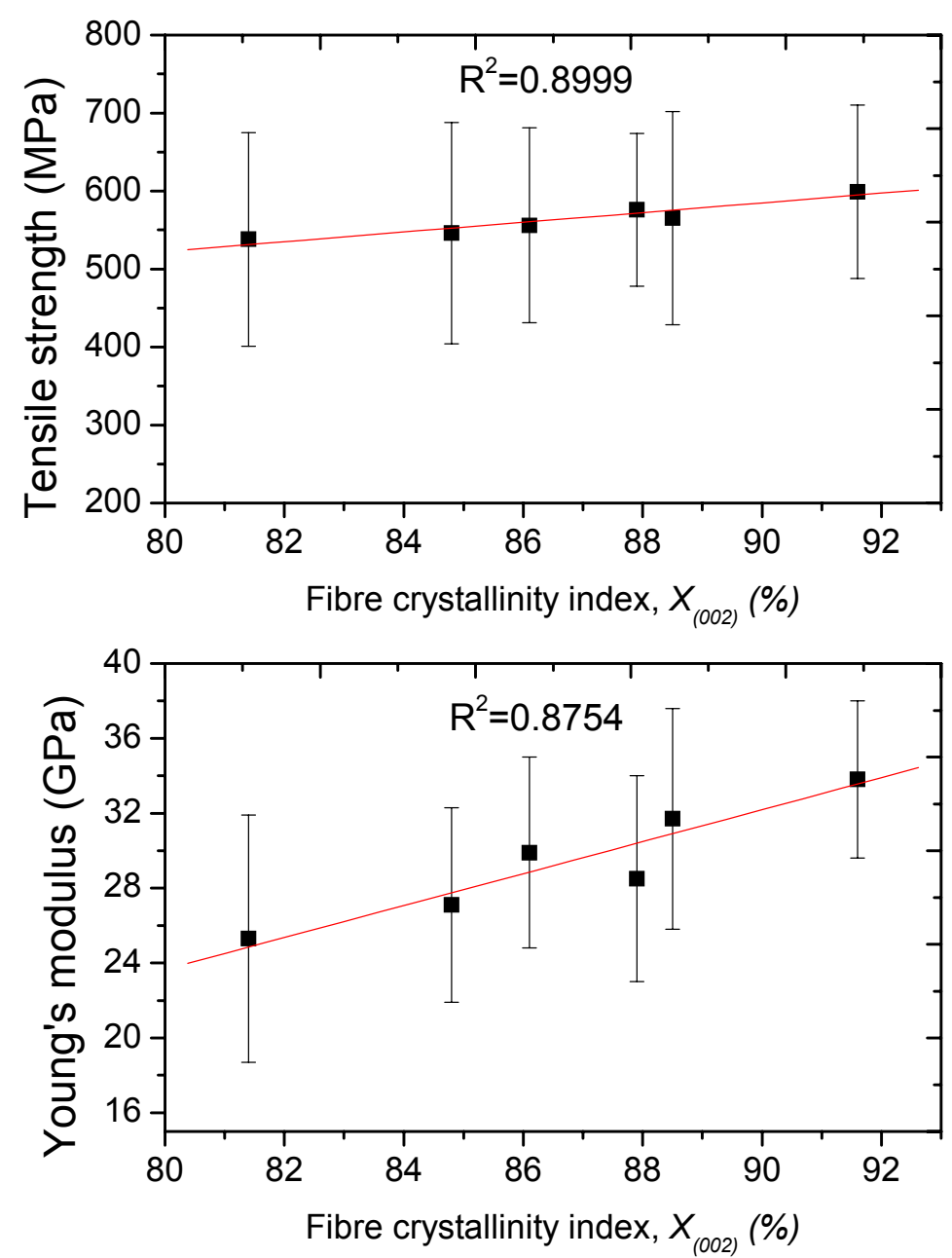

Fig. 14. 
Table 1

FT-IR transmittance peaks for untreated and treated hemp fibres.

\begin{tabular}{|c|c|c|}
\hline Possible assignments & Transmittance peak $\left(\mathrm{cm}^{-1}\right)$ & References \\
\hline$-\mathrm{OH}$ bond stretching & 3410 & 17,18 \\
\hline $\mathrm{C}-\mathrm{H}$ stretching vibration & 2916 & 18,20 \\
\hline $\begin{array}{l}>\mathrm{C}=\mathrm{O} \text { stretching of carboxylic acid } \\
\text { or ester }\end{array}$ & 1732 & $1,17,19$ \\
\hline Absorbed water & 1639 & 1,18 \\
\hline $\mathrm{CH}_{2}$ symmetric bending & 1425 & 18,19 \\
\hline $\mathrm{O}-\mathrm{H}$ bending & 1322 & 1,18 \\
\hline $\mathrm{C}-\mathrm{O}$ stretching of acetyl (lignin) & 1247 & 1,18 \\
\hline$\beta$-glucosidic linkage & 892 & 1,19 \\
\hline $\begin{array}{l}>\mathrm{C}=\mathrm{O} \text { stretching of ester ( in } \mathrm{ACY} \\
\text { fibres) }\end{array}$ & 1743 & 23 \\
\hline $\begin{array}{l}>\mathrm{C}=\mathrm{O} \text { stretching of ester ( in } \mathrm{MA} \\
\text { fibres) }\end{array}$ & 1721 & 24,25 \\
\hline $\begin{array}{l}-\mathrm{Si}-\mathrm{C}-\text { symmetric stretching (in } \\
\text { silane treated fibres) }\end{array}$ & 780 & 6,17 \\
\hline $\begin{array}{l}-\mathrm{Si}-\mathrm{O}-\mathrm{Si}-\text { symmetric stretching (in } \\
\text { silane treated fibres) }\end{array}$ & 708 & 6,17 \\
\hline $\begin{array}{l}-\mathrm{Si}-\mathrm{O}-\mathrm{C}-\text { stretching } \text { (in silane } \\
\text { treated fibres) }\end{array}$ & 1203 & 6,17 \\
\hline
\end{tabular}


Table 2

Average diameter and density of the untreated and treated hemp fibres

\begin{tabular}{lll}
\hline Sample & Density $\left(\mathrm{g} / \mathrm{cm}^{3}\right)$ & Diameter $(\mu \mathrm{m})$ \\
\hline FB & $1.401( \pm 0.0011)$ & $31.5( \pm 7.3)$ \\
ALK & $1.423( \pm 0.0009)$ & $25.8( \pm 5.2)$ \\
ACY & $1.437( \pm 0.0013)$ & $28.1( \pm 6.5)$ \\
MA & $1.431( \pm 0.0010)$ & $27.7( \pm 5.8)$ \\
SIL & $1.447( \pm 0.0008)$ & $28.4( \pm 6.1)$ \\
ALKSIL & $1.459( \pm 0.0011)$ & $25.3( \pm 5.5)$ \\
\hline
\end{tabular}

